B I O S C I E N C E

J O U R N A

\title{
CHARACTERIZATION AND PLASTICITY OF WHARTON'S JELLY MESENCHYMAL STEM CELLS OF GOAT
}

Gustavo Cardoso da Silva NEVES ${ }^{1}$ (D), Napoleão Martins ARGOLO NETO² (iD, Maíra Soares FERRAZ ${ }^{3}$ (D), Clautina Ribeiro de Moraes da $\operatorname{COSTA}^{4}(\mathbb{D})$, Andressa Rêgo da ROCHA ${ }^{5}$ (i), Huanna Waleska Soares RODRIGUES ${ }^{6}$ (i), Felipe de Carvalho NUNES 7 (i), Camila Ernanda Sousa de CARVALHO ${ }^{6}$ id , Miguel Ferreira CAVALCANTE FILHO ${ }^{8}$ (D), Danilo José Ayres de MENEZES 9 (D), Maria Acelina Martins de CARVALHO ${ }^{8}$ (D)

\footnotetext{
${ }^{1}$ Postgraduate Program in Biotechnology, Federal University of Piauí, Teresina, Piauí, Brazil.

2 Department of Clinical and Veterinary Surgery, Federal University of Piauí, Teresina, Piauí, Brazil.

3 Department of Morphology, Federal University of Piauí, Teresina, Piauí, Brazil.

4 Coordination of Natural Sciences, Humanities and Letters, Federal Institute of Education, Science and Technology of Piauí, Teresina, Piauí, Brazil.

${ }^{5}$ Coordination of Natural Sciences, Humanities and Letters, Federal Institute of Education, Science and Technology of Piauí, Cocal, Piauí, Brazil.

${ }^{6}$ Postgraduate Program in Animal Science, Federal University of Piauí, Teresina, Piauí, Brazil.

${ }^{7}$ Graduate Course in Pharmacy, Maurício de Nassau University Center, Teresina, Piauí, Brazil.

8 Department of Veterinary Morphophysiology, Federal University of Piauí, Teresina, Piauí, Brazil.

${ }^{9}$ Department of Morphology, Federal University of Rio Grande do Norte, Natal, Rio Grande do Norte, Brazil.
}

Corresponding author:

Maria Acelina Martins de Carvalho

Email: mcelina@ufpi.edu.br

How to cite: NEVES, G.C.S., et al. Characterization and plasticity of wharton's jelly mesenchymal stem cells of goat. Bioscience Journal. 2021, 37, e37002. https://doi.org/10.14393/BJ-v37n0a2021-50386

\begin{abstract}
Mesenchymal stem cells (MSCs), obtained from several anatomical sites, have already been described, characterized and used in therapeutic models for tissue repair. The umbilical cord mesenchymal stem cells, represented by cells from arteries and veins walls, as well as Wharton's jelly are easy to be obtained, highly available, require no invasive procedure, do not present risk to donors and do not present ethical limitation. The aim of this research was to analyze the plasticity of Wharton's jelly mesenchymal stem cells (WJ-MSCs) of goat, evaluating their behavior in vitro and characterizing them immunophenotypically. Thus, tests were performed on colony forming units, viability and cell growth curve, flow cytometry analysis and plasticity potential. Goat umbilical cord matrix cells exhibited fibroblastoid morphology with colony formation and self-renewal ability, always maintaining their undifferentiated state up to the eighth passage (P8). The growth curve kinetics exhibited the LAG, LOG, and DECAY phases, without displaying a PLATEAU phase. The plasticity assay demonstrated positive differentiation for osteogenic, adipogenic and chondrogenic lines, characterized by the synthesis of intracytoplasmic granules or extracellular matrix with the presence of calcium, lipids and proteoglycans. Flow cytometry demonstrated the expression of CD90 and CD105; absence of CD14 expression. It is concluded that the cell population isolated from the Wharton's jelly of goat constitutes a representative sample of mesenchymal stem cells, with great possibilities in the field of regenerative and reproductive medicine.
\end{abstract}

Keywords: Cell Culture. Flow Cytometry. Lineage Differentiation. Mesenchymal Stem Cells. Umbilical Cord Matrix. 


\section{Introduction}

Mesenchymal Stem Cell therapy is an innovative alternative of cell therapy proposed by several studies in the regenerative medicine area, for the treatment of various human and animal diseases, chronicdegenerative or not. This proposal is based on: the in vitro characteristics of low immunogenicity, since they do not express significant levels of the Major Histocompatibility Complex type 2; of immunomodulatory capacity, since they can induce immunosuppression through the production of several chemokines with antiinflammatory properties; in addition to the capacity of plasticity, demonstrated by differentiation in distinct cell lines (Costa et al. 2017; Rocha et al. 2017; Sironi et al. 2017; Xie et al. 2018). MSCs are defined by the ability to self-renew and differentiate into specialized cell types. These cells are characterized in vitro by fibroblastoid morphology, adhesion to the plastic surface and ability to differentiate into other mesodermal lines, such as adipocytes, osteocytes and chondrocytes (Da Rocha et al. 2012).

The umbilical cord is a transitional organ responsible for the nutritional supply to the embryo and/or fetus in the maternal uterus, consisting of several structures: the amniotic membrane, blood vessels and Wharton's jelly (Argôlo Neto et al. 2016; Bastawrous et al. 2016).

Mesenchymal stem cells derived from umbilical cord (UC-MSCs) and from fetal annexes are easy to be obtained, readily available, do not require invasive procedures, pose no risk to donors and have low potential for transmission of infections (Gauthaman et al. 2012; Bastawrous et al. 2016; El-Ashmawy et al. 2018). Moreover, they do not express costimulatory molecules, so they have low immunogenic and tumorigenic potential, unlimited source and have a high differentiation potential, MSCs are considered as potential therapeutic agents for the treatment of numerous diseases (Taghizadeh et al. 2011; Volarevic et al. 2014).

The UC-MSCs have become an attractive source of MSCs because they are abundant, accessible, possess high isolation potential and proliferation rates and can be obtained from fetal tissues, isolated at different gestational ages (Mohammadi et al. 2018). Considering their availability and the non-invasive harvesting procedure, UC-MSCs are a promising source. Studies have shown that MSCs derived from Wharton's Jelly (WJ-MSCs) offer better clinical utility because of their unique beneficial properties compared to other sources (Gauthaman et al. 2012; Desancé et al. 2018).

Among the animal models proposed for studies with UC-MSCs, goats stand out for their rusticity, docility, reduced size, and morphological similarity of internal organs. These characteristics favor biomedical research for both human and animal health and the improvement of reproductive biotechniques (Gugjoo et al. 2020).

The aim of this research was to evaluate the expansion, cellular kinetics, plasticity, immunophenotypic characterization and cellular cryopreservation, under in vitro culture for a better understanding of the morphological mechanisms of WJ-MSCs of goats.

\section{Material and Methods}

Two umbilical cords of undefined breed goat fetus (Capra hircus) from normal birth in the municipality of Teresina, Piauí, Brazil were used. The samples were collected, washed four times in Phosphate Buffered Saline (PBS) enriched with 10\% of antibiotics Penicillin / Streptomycin 5,000 U/mL LGC Biotecnologia ${ }^{\circledast}$, then conditioned in $50 \mathrm{ml}$ conical tubes inside refrigerated thermal box for transport. For this purpose, supplemented transport medium was used with 74\% DMEM/F12, 15\% fetal bovine serum (FBS), 1\% MEM NEAA non-essential amino acids Gibco $^{\circledR}$ and $10 \%$ antibiotics, Penicillin/Streptomycin 5000 $\mathrm{U} / \mathrm{mL}$ LGC Biotechnology ${ }^{\circledR}$.

The matrices of the umbilical cords and fetal annexes were washed in PBS solution enriched with $10 \%$ of LGC Biotechnology ${ }^{\circledR}$ antibiotics. Wharton's jelly was fragmented with a scalpel, placed in a $15 \mathrm{ml}$ sterilized conical tube and centrifuged (Model $280 \mathrm{R}$ centrifuge, Excelsa ${ }^{\circledR}$ ) at $20^{\circ} \mathrm{C} / 1100 \mathrm{rpm}$ for 10 minutes. The pellet was resuspended and seeded in 6-well plates with medium of culture, modified from Moshrefi et al. (2018), supplemented with 78\% DMEM/F12, 20\% FBS, 1\% NEAA Gibco ${ }^{\circledR}, 1 \%$ LGC Biotechnology $^{\circledR}$. The cells were cultured in a humidified atmosphere (95\%) containing $5 \% \mathrm{CO}_{2}$, at $37 \circ \mathrm{C}$, for 24 hours to verify cell adhesion.

The culture medium was changed every three days, the culture was monitored until the cells reached $75 \%$ confluency. Then, they were submitted to the action of $0.25 \%$ Trypsin-EDTA (Gibco ${ }^{\circledR}$ ), centrifuged and 
plated in bottles of $25 \mathrm{~cm}^{2}$ and later, in bottles of $75 \mathrm{~cm}^{2}$, respecting the criterion of maintaining double the original area. Cell cultures of Wharton jelly were expanded to the eighth passage (P8), photographed under inverted microscope (COLEMAN NIB-100 ${ }^{\circledR}$ ).

For freezing, the WJ-MSCs, from the third passage (P3) to P8, were subjected to the enzymatic action of Trypsin. The resulting pellet of cells was resuspended in 45\% DMEM/F12 freezing medium supplemented, $45 \%$ FBS Gibco ${ }^{\circledR}$ and $10 \%$ dimethyl sulfoxide (DMSO), Sigma-Aldrich ${ }^{\circledR}$. The cells were conditioned at the concentration of $1 \times 10^{6} \mathrm{cells} / \mathrm{mL} / \mathrm{cryotube}$, and were subsequently transferred to a freezer at $-80^{\circ} \mathrm{C}$ overnight. After 24 hours, the cryotubes were packed in liquid nitrogen $-196^{\circ} \mathrm{C}$, for three months.

Upon thawing the cryotubes were withdrawn from the nitrogen canister and remained at room temperature in order to reduce cell stress during an abrupt temperature variation that could trigger in the water bath. The cells were then conditioned in a $15 \mathrm{ml}$ conical tube with twice the culture medium, centrifuged and the pellet resuspended and plated in supplemented culture medium.

Cell concentration and viability were determined by the Trypan Blue dye exclusion method. After trypsinization, $50 \mu \mathrm{L}$ of the cell suspension was mixed in $50 \mu \mathrm{L}$ of the Trypan Blue solution, a $12 \mu \mathrm{L}$ aliquot was placed in a hemocytometer and observed under an optical microscope (objective 10X). Cell viability was determined by the ratio between the amount of live, uncolored cells and the total amount of cells.

The CFU-C assay was performed at zero passage (PO), after mechanical dissociation. The resulting cell pellet was seeded into a 6-well plate with supplemented culture medium. The cultures were evaluated daily with the first exchange of medium performed with three days. After six days the cultures were fixed on the plate with $10 \%$ paraformaldehyde for 30 minutes, then submitted to Giemsa staining for 2 minutes. To remove excess dye washes were performed twice with PBS.

Cell expansion and replication capacity was evaluated by saturation growth curve, performed in triplicate. Five six-well plates were plated with $1 \times 10^{4}$ cells $/ \mathrm{ml}$ in the sixth passage (P6) in each well. The plates were incubated and the culture medium was changed every 72 hours. Cell growth was evaluated at 24-hour intervals for 10 days. Daily three wells were trypsinized and neutralized with twice the culture medium, placed in $15 \mathrm{ml}$ conical tubes and centrifuged, evaluating the concentration and viability determined by the method of Trypan blue dye. After trypsinization, $50 \mu \mathrm{L}$ of the cell suspension was mixed in $50 \mu \mathrm{L}$ of the Trypan Blue solution. A $12 \mu \mathrm{L}$ aliquot was placed in a hemocytometer and observed under an optical microscope (objective 10X). All culture medium was replaced every three days and three culture wells, trypsinized daily, evaluating cell viability and concentration.

For flow cytometry CD14, CD90 and CD105 antibodies were used. Cells from third pass (P3) were submitted to flow cytometry in order to guarantee a sufficient population of undifferentiated cells for their characterization. Cells were trypsinized, followed by centrifugation resuspended in PBS at a concentration of $1 \times 10^{5}$ cells $/ \mathrm{ml}$. For each antibody, $1 \times 10^{5}$ cells were used. Each tube was washed with $1 \mathrm{~mL}$ of FACS DBPS (Dubelco's Phosphate Buffer Solution) containing 0.1\% BSA, centrifuged at $600 \mathrm{rpm}$ for 8 minutes. The cells were incubated with the primary antibody (diluted 1:100) for 30 minutes at room temperature. In sequence, they were washed once with $1 \mathrm{ml}$ FACS buffer for removal of excess antibody and incubated with secondary antibody (diluted 1:300) for 30 min. Cells were washed with FACS buffer and fixed with $4 \%$ buffered paraformaldehyde solution. Samples were analyzed on a flow cytometer (Guava EasyCyte System, Guava Technologies). Populations were estimated by the percentage of cells expressing each of the markers in relation to the total of cells acquired.

Cell differentiation analyzes were performed with cells in seventh passage (P7) after freezing. $10^{4}$ cells $/ \mathrm{ml}$ were plated and cultured with culture medium until $80 \%$ confluency. The differentiation was then induced by replacing the culture medium with the Stempro ${ }^{\circledR}$ Osteogenesis Differentiation Kit according to the instructions suggested by the manufacturer.

In summary, cellular aliquots of $10^{5}$ cells $/ \mathrm{mL}$ were plated, organized in three triplicates, in wells containing DMEM/F12 culture medium supplemented and incubated for 72 hours at $5 \% \mathrm{CO}$, and 37 으. For each triplicate, a differentiation test was performed, using a negative control for both. After 72 hours, for each triplicate, the culture medium was replaced by the corresponding differentiation medium (osteogenic, adipogenic, or chondrogenic). 
For osteogenic differentiation, triplicate was kept incubated for 21 days, renewing the differentiation medium every 48 hours. After this period, the medium was discarded, the cells fixed with formalin buffered at $10 \%$, and then stained with Alizarin Red S.

For adipogenic differentiation, triplicate was kept incubated for 7 days, renewing the differentiation medium every 48 hours. The cells were fixed with $10 \%$ buffered formalin and stained with Oil Red 0.

During chondrogenic differentiation, the cells were incubated for 14 days, renewing the differentiation medium every 48 hours. The cells were fixed with paraformaldehyde at $10 \%$ for four hours, washed with $70 \%$ alcohol, and submitted to conventional histotechnique. Histological sections of $3 \mu \mathrm{m}$ thickness were obtained, stained with Alcian Blue overnight.

The statistical evaluation was performed using the electronic data sheet (Excel ${ }^{\circledR}$ ) and the statistical analysis program $\left(\mathrm{SAS}^{\circledast}\right)$, version 5.0. The averages and standard deviations of cell viability and kinetics were evaluated. The level of rejection of the null hypothesis was $5 \%(p \leq 0.05)$ for the statistical analysis.

This study was approved by the Ethics Committee on the Use of Animals (CEUA) of the Federal University of Piauí (Permit Number 117/15).

\section{Results}

Cells derived from Wharton's jelly of goats showed adherence to the plastic surface of the flask during the first days of cell culture, with heterogeneous morphology, spindle shape and small rounded, with release of cells with fibroblastoid characteristics, released by explants. Subsequently, the culture became homogeneous. They remained in primary culture for 18 days, when they reached $75 \%$ confluency, the passages were made. A sample remained until reaching $100 \%$ confluency with homogeneous characteristics at 21 days. As for the long-term viability, cell expansion was performed, and the cells grown to P8 were always fibroblastoid characteristic morphology and remained undifferentiated with spherical nuclei and monolayer proliferation (Figure 1).

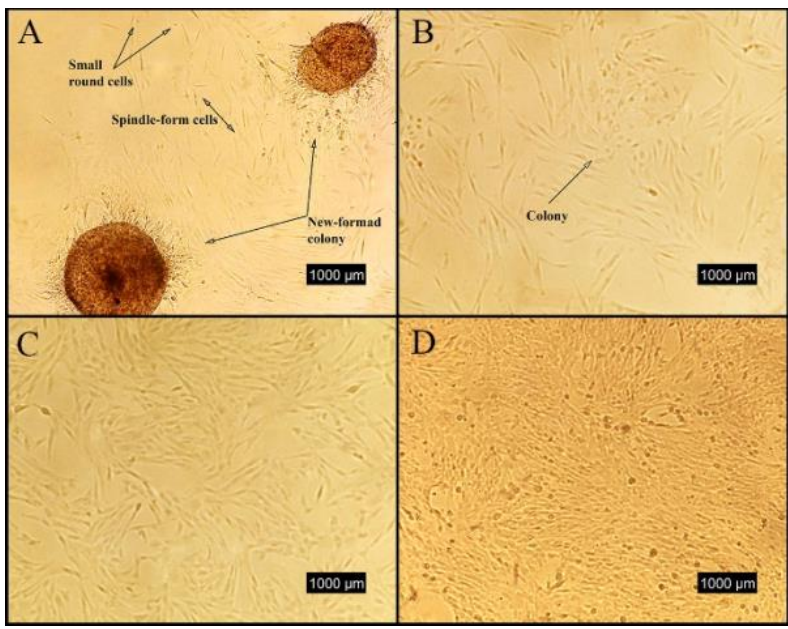

Figure 1. Photomicrography of cells isolated from Wharton jelly from goats. (A) Fifth day. Culture in isolation phase, demonstrating cellular heterogeneity, with the presence of mononuclear and fusiform cells. Fusiform cells are observed detaching from the margins of the explants, organizing themselves as colonies adjacent to them. (B) Fourteenth day. Culture in the expansion phase. A colony of fusiform cells. (C) Nineteenth day. Culture in the expansion phase. Homogeneous cell monolayer with $80 \%$ confluence, composed of adherent cells with fibroblastoid morphology. (D) Twenty-first day. Cell monolayer with maximum confluence, exhibiting cell overlap, and compression.

Cell kinetics was characterized by LAG phases on days 1 and 2, LOG on days 3, 4, 5, 6, 7, 8 and 9 and DECAY from day 10. In the LAG phase, cell proliferation and differentiation, values close to the initial sowing concentration being maintained. In LOG, a significant exponential increase in cell concentration occurred. The PLATEAU phase was not observed under the conditions of this study. The DECAY phase showed very low cell proliferation and cell concentrations declined. The LAG, LOG and DECAY stages are evident (Figure 2). 


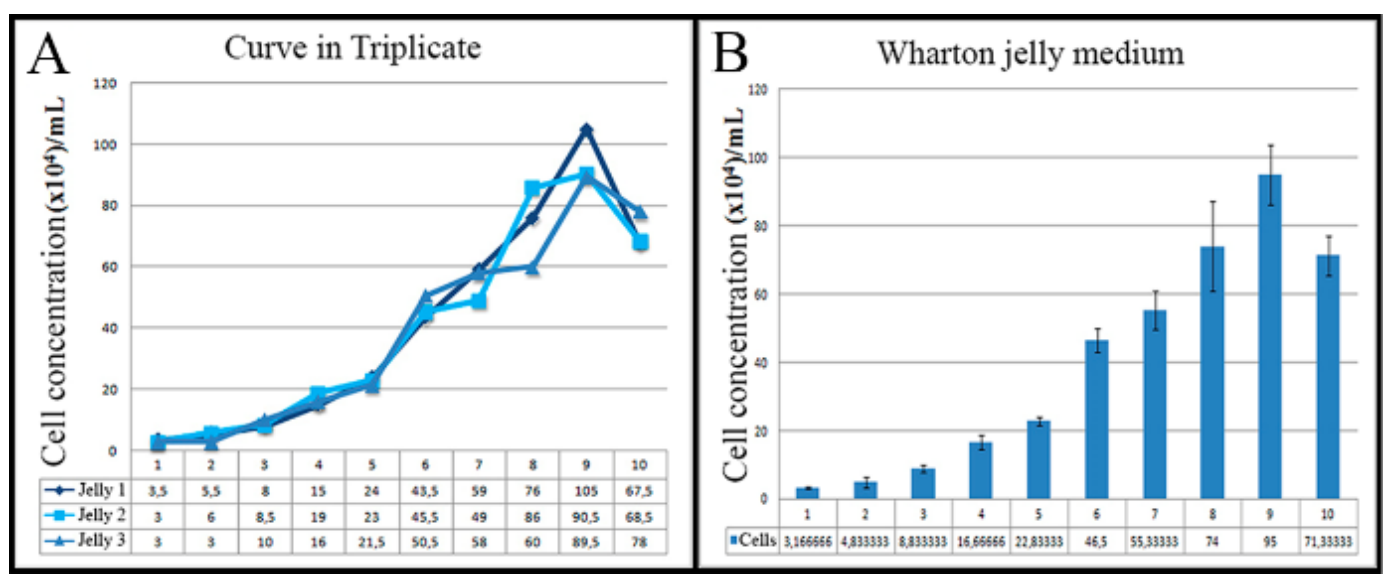

Figure 2. Graphic representation of cellular kinetics in saturation growth curve. Cell concentration is defined in the $\times 10^{4} / \mathrm{mL}$ scale. (A) Individualized values for each cellular sampling, in triplicate, over ten days of culture. A short latency phase (LAG) is identified on days 1 and 2, followed by a logarithmic phase (LOG) from the third to the ninth day and the beginning of a subsequent decay phase (DECAY). (B) Display of the weighted average and its respective standard deviations of the cell concentration over ten days of culture.

In the evaluation of CFU-C after plating the samples of mononuclear cells, cells with adherent plastic characteristics were observed, remaining a potential of growth between them, showing coloration with slight variation of pink to blue and morphology of the homogenous cultures, manifesting flat cells, fibroblastoids, straight and long, with more than 2 extensions, showing the most widely scattered cell body and well-rounded nuclei (Figure 3).

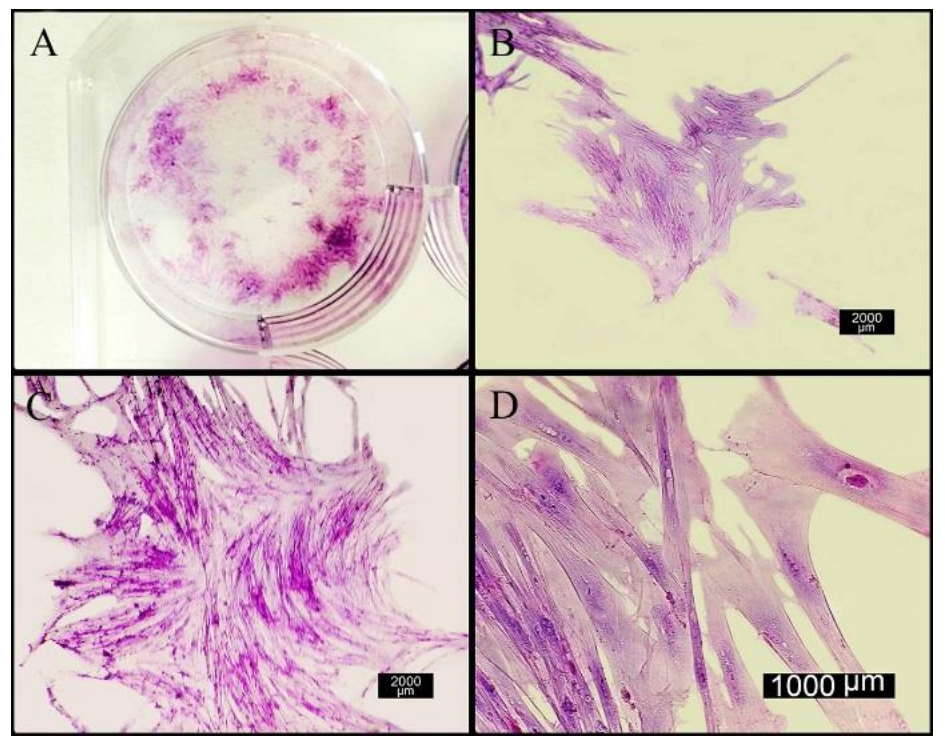

Figure 3. Assay of fibroblast colonyforming units (CFU-C) of Wharton's jelly of goat subjected to Giemsa staining. (A) Panoramic macroscopic view of the colonies in the well. (B/C) Formation of colonies well delimited, homogeneous in the fibroblastoid format. (D) Intense cellular interaction and welldefined nucleus.

The samples of Wharton's jelly of goat evaluated by flow cytometry showed no labeling for the control cells, cells that did not insert the surface markers for CD14, CD90 and CD105. For the cells incubated with markers, they showed expression of CD90 and CD105, and absence of expression of CD14, as shown in (Figure 4).

The culture of stem cells from Wharton's jelly carried out in inducing medium of osteogenic differentiation for 21 days resulted in the production of extracellular calcium crystals identified in red by Alizarin Red staining (Figure 5 A-B). Cells cultured in adipogenic differentiation medium for 7 days demonstrated morphological changes resulting in a three-dimensional shape similar to a tissue and accumulation of intracytoplasmic lipid droplets stained in red by Oil Red $\mathrm{O}$ staining. In the histological analysis of the chondrogenic culture during 14 days, it was possible observe the cell matrix with a very 
intense bluish coloration due to the interaction of the dye with the glycosaminoglycans expressed during the differentiation.

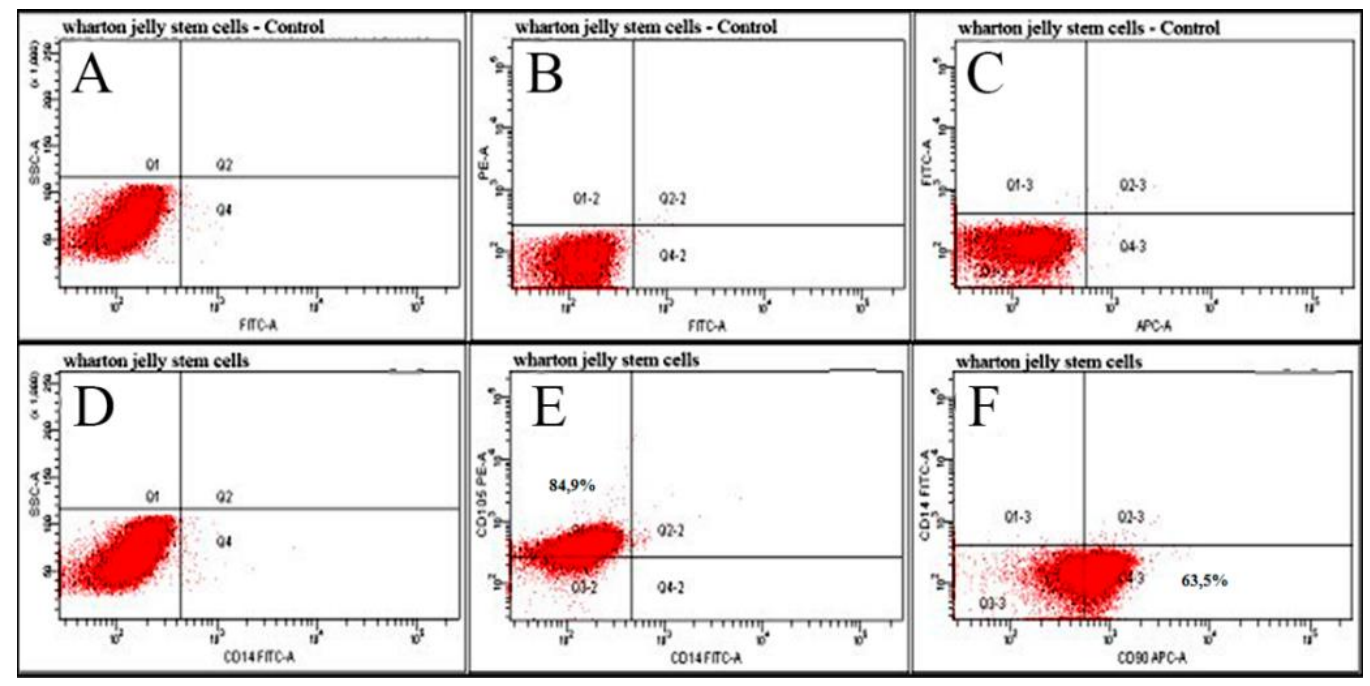

Figure 4. Flow cytometry analysis of cells isolated from Wharton's jelly of goat for expression of CD14, CD105, and CD90 markers. (A), (B) and (C) Negative controls, evidencing the absence of expression of markers. (D) The sample tested for CD14 marker expression, demonstrating the absence of it. (E) and (F) Sample tested for the expression of CD105 (84.9\%) and CD90 (63,5\%) markers, respectively, demonstrating positive marking for them. Cell viability found was $98 \%$.

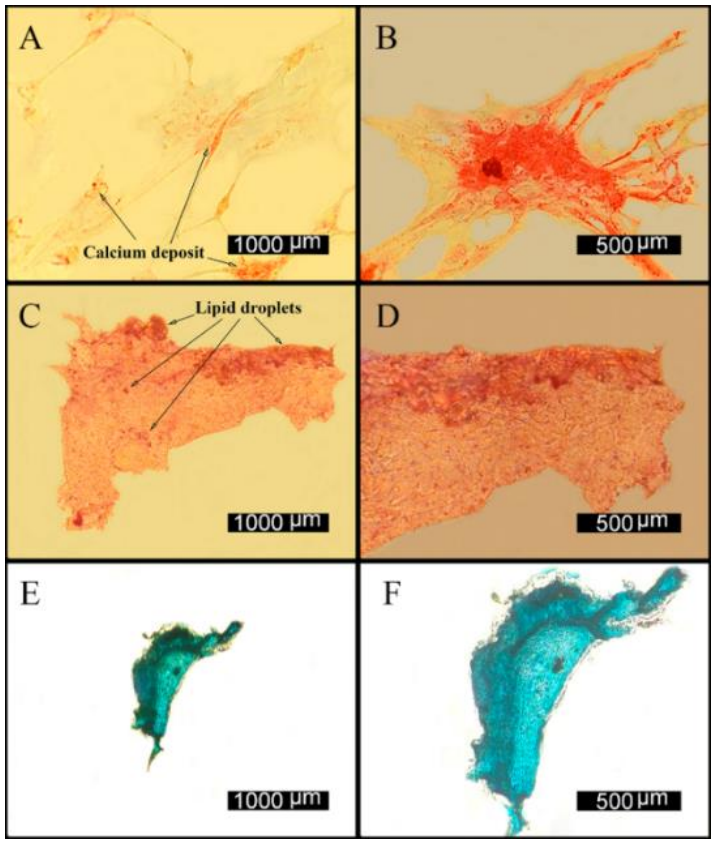

Figure 5. Plasticity assay of cells isolated from Wharton's jelly of goat submitted to osteogenic, adipogenic, and chondrogenic differentiation. (A) Positive osteogenic differentiation. Calcium deposits composing the extracellular matrix, stained by Alizarin Red, are identified. (B) Cell with osteoblast-like morphology, showing cytoplasmic projections and presence of intracytoplasmic granules, positive for the presence of

calcium, by staining by Alizarin Red. (C) and (D) Positive adipogenic differentiation. Presence of

intracytoplasmic lipids stained by Oil Red, present in a large colony of cells similar to adipocytes. Cell overlap and staining intensity make it challenging to identify cytoplasmic boundaries between cells. (E) and

(F) Positive chondrogenic differentiation. Identification of the presence of proteoglycans in the extracellular matrix, revealed by the intense blue coloration by Alcian Blue.

\section{Discussion}

The umbilical cord represents the main source of undifferentiated stem cells from both the hematopoietic and mesenchymal lineages. For a long time, this fetal annex discarded after birth and 
neglected as an anatomical niche of multipotent cells (Donofrio et al. 2005). After the discovery of this source of stem cells and their potential for differentiation in vitro, the use of umbilical MSCs became relevant in cell therapy. These cells are able to differentiate significantly at morphological and genetic levels (De Schauwer et al. 2011; Sargiacomo et al. 2017).

The most commonly used techniques for obtaining MSCs are enzymatic digestion, explants and mechanical dissociation (Puranik et al. 2012). Wharton' jelly of the umbilical cord is a mucoid connective tissue, from which MSCs can be easily isolated and expanded. The isolation of WJ-MSCs of goats occurred from the mechanical dissociation and subsequent centrifugation of the gelatinous tissue to the beginning of the cell culture, which allowed the minimum of practicable stress to the tissue fragments, which allowed the appearance of fibrosblast colonies forming units with high clonogenic potential, intense cellular interaction and well defined cell nucleus.

In this study, the phenotypic characteristics of the WJ-MSCs of goats were presented, confirming the success of the isolation and expansion, showing adherence to the plastic in vitro culture, for long periods, until the eighth passage, without losing the high potential of clonogenicity, with fibroblastic characteristics. Results similar to those of Moshrefi ey al. (2018), also in goats, which indicate that the Wharton's jelly has a large population of mesenchymal stem cells with fibroblastic characteristics and high potential for clonogenicity.

Cells from Wharton's jelly of goat, in primary culture, were derived from the release of explants, and exhibited typical heterogeneous fibroblastoid cell morphology and smaller cells. Following the passages a homogeneous culture was observed, remaining only fibroblastoids cells, with dense colonies until reaching confluence of $100 \%$. These findings are consistent with those of Donders et al. (2018) who reported characteristic cell viability in the WJ-MSCs culture of humans, cell growth derived from the release of explants, heterogeneous culture with fibroblastoid morphology, and small cells, often triangular and with formation of colonies in dense cultures until reaching $100 \%$ of confluence.

The growth curve model adopted by saturation subjected cultures to relevant metabolic stress, since it did not use rebound to limit cell expansion and, consequently, exhaustion of the culture medium. Nevertheless, WJ-MSCs showed a logarithmic increase over nine days, with no Plateau Phase display, before showing a reduction in cell concentration (Figure 2). This characteristic is not uncommon among mesenchymal stem cell lines, and studies with bone marrow, adipose tissue, and dental pulp lineages have commonly demonstrated similar evidence (Argôlo Neto et al. 2016; Rocha et al. 2019; Soares et al. 2019). This observation raises the possibility that this group of somatic stem cells may present relevant metabolic adaptability.

In the analysis of the immunophenotypic profile by flow cytometry of expanded cultures, the WJMSCs demonstrated expression for CD90 and CD105, with no expression for CD14 and, on differentiation induction, presented positivity for the three strains in mature cells (osteocytes, adipocytes and chondrocytes). These data coincide with the information described by Mohammadi et al. (2018) for MSCs, isolation of fetal and adults tissues, adhesion to plastic, expression of CD105, CD73 and CD90, without expression of CD14, CD34, CD45 and HLA-DR, as well as differentiation capacity in osteogenic, chondrogenic, and adipogenic. On other hand, in the study by Moshrefi et al. (2018), about the Wharton's jelly mesenchymal stem cells of goats, there are evident uncertainties regarding the confirmation of a stem cell, in accordance with the criteria adopted to characterize it, since they do not provide data on the differentiation potential and expression and absence of expression of surface markers. However, in this study with goat WJ-MSCs, all characteristics of a stem cell were proven.

Under culture conditions, the cells consume mainly glucose as a substrate for the generation of cellular energy (ATP). High glucose rate is required for the growth and replication of the cells, supplied by the use of supplemented culture medium, with exchanges performed every three days. These metabolic characteristics were evidenced for the culture of WJ-MSCs from goat in this study, similarly to the description by Prieto et al. (2016) in mesenchymal cells. These authors observed metabolic changes during in vitro cell culture, indicating that MSCs increase anaerobic metabolism along passages, a significant shift in energy metabolism throughout the growth of MSCs in culture.

The WJ-MSCs of goat have a high homogeneous rate of cell proliferation, undifferentiated for a long period, presenting a viable growth curve for in vitro culture, expressing cell surface markers, and have cell 
differentiation potential for the osteogenic, adipogenic and chondrogenic strains, and can be used in cell therapy.

\section{Conclusions}

Wharton's jelly of goat represents a potential source of adult, multipotent stem cells capable of differentiating into mesodermal lines, constituting a representative sample of stem cells, which are possible for its therapeutic use. The understanding and optimization of the process of expansion and differentiation of Wharton's jelly mesenchymal stem cells of goats contributed to the maximization of cell yield and decrease of the total costs of the cellular system in vitro. Thus, the goat may be a relevant animal model applied to the preclinical studies of this cellular niche, generating great possibilities in the field of regenerative and reproductive medicine therapies.

Authors' Contributions: NEVES, G.C.S.: conception and design, acquisition of data, analysis and interpretation of data, drafting the manuscript, final approval; ARGOLO NETO, N.M.: acquisition of data, analysis and interpretation of data, drafting the manuscript, final approval; FERRAZ, M.S.: analysis and interpretation of data, drafting the manuscript, final approval; COSTA, C.R.M.: analysis and interpretation of data, drafting the manuscript, final approval; ROCHA, A.R.: analysis and interpretation of data, drafting the manuscript, final approval; RODRIGUES, H.W.S.: drafting the manuscript, final approval; NUNES, F.C.: drafting the manuscript, final approval; CARVALHO, S.E.S.: drafting the manuscript, final approval; CAVALCANTE FILHO, M.F.: acquisition of data, drafting the manuscript, final approval; MENEZES, D.J.A.: acquisition of data, drafting the manuscript, final approval; CARVALHO, M.A.M.: conception and design, analysis and interpretation of data, drafting the manuscript, final approval.

Conflicts of Interest: The authors declare no conflicts of interest.

Ethics Approval: Ethics Committee on the Use of Animals (CEUA) of the Federal University of Piauí (Permit Number 117/15).

Acknowledgments: The authors would like to thank the funding for the realization of this study provided by CNPq (Conselho Nacional de Desenvolvimento Científico e Tecnológico - Brasil), Finance Code 407300/2013-9. The authors are very grateful to the Federal University of Piauí (UFPI) for the support of infrastructure and technical.

\section{References}

ARGÔLO NETO, N.M., et al. Isolation, expansion, differentiation and growth kinetics essay in mesenchymal stem cells culture from the bone marrow of collared peccaries (Tayassu tajacu). Acta Scientiae Veterinariae. 2016, 44(1), 1-11. https://doi.org/10.22456/1679-9216.80850

BASTAWROUS, M., et al., 2016. Wharton's jelly stem cells. In: FAUZA, D.O. and BANI, M., eds. Fetal Stem Cells in Regenerative Medicine. New York: Springer, pp. 257-276. https://doi.org/10.1007/978-1-4939-3483-6

COSTA, C.R.M., et al. Labeling of adipose-derived stem cells with quantum dots provides stable and long-term fluorescent signal for ex vivo cell tracking. In Vitro Cellular \& Developmental Biology-Animal. 2017, 53(4), 363-370. https://doi.org/10.1007/s11626-016-0121-2

DA ROCHA, A.R., et al. Hematopoietic progenitor constituents and adherent cell progenitor morphology isolated from black-rumped agouti (Dasyprocta prymnolopha, Wagler 1831) bone marrow. Microscopy Research and Technique. 2012, 75(10), 1376-1382.

https://doi.org/10.1002/jemt.22077

DE SCHAUWER, C., et al. Markers of stemness in equine mesenchymal stem cells: a plea for uniformity. Theriogenology. 2011, 75(8), 14311443. https://doi.org/10.1016/j.theriogenology.2010.11.008

DESANCÉ, M., et al. Chondrogenic differentiation of defined equine mesenchymal stem cells derived from umbilical cord blood for use in cartilage repair therapy. International Journal of Molecular Sciences. 2018, 19(2), 537. https://doi.org/10.3390/ijms19020537

DONDERS, R., et al. Human Wharton's Jelly-derived stem cells display a distinct immunomodulatory and proregenerative transcriptional signature compared to bone marrow-derived stem cells. Stem Cells and Development. 2018, 27(2), 65-84.

https://doi.org/10.1089/scd.2017.0029

DONOFRIO, G., et al. Susceptibility of bovine mesenchymal stem cells to bovine herpesvirus 4. Journal of Virological Methods. 2005, 127(2), 168-170, 2005. https://doi.org/10.1016/i.jviromet.2005.02.019

EL-ASHMAWY, N.E., et al. Effect of human umbilical cord blood-derived mononuclear cells on diabetic nephropathy in rats. Biomedicine \& Pharmacotherapy. 2018, 97, 1040-1045. https://doi.org/10.1016/j.biopha.2017.10.151

GAUTHAMAN, K., et al. Human umbilical cord Wharton's jelly stem cell (hWJSC) extracts inhibit cancer cell growth in vitro. Journal of Cellular Biochemistry. 2012, 113(6), 2027-2039. https://doi.org/10.1002/jcb.24073

GUGJOO, M.B., et al. Goat mesenchymal stem cell basic research and potential applications. Small Ruminant Research. 2020, 183, 106045.

https://doi.org/10.1016/j.smallrumres.2019.106045

MOHAMMADI, M., et al. Effect of gestational age on migration ability of the human umbilical cord vein mesenchymal stem cells. Advances in Medical Sciences. 2018, 63(1), 119-126. https://doi.org/10.1016/j.advms.2017.08.002 
MOSHREFI, M., et al. Isolation and characterization of mesenchymal cells isolated from caprine umbilical cord matrix. Animal Reproduction. $2018,7(4), 367-372$.

PRIETO, P., et al. Cell expansion-dependent inflammatory and metabolic profile of human bone marrow mesenchymal stem cells. Frontiers in Physiology. 2016, 7, 548. https://doi.org/10.3389/fphys.2016.00548

PURANIK, S.B., et al. Isolation of mesenchymal-like cells from Wharton's jelly of umbilical cord. International Journal of Pharmaceutical, Chemical and Biological Sciences. 2012, 2(3), 218-224.

ROCHA, A.R., et al. Immunophenotyping, plasticity tests and nanotagging of stem cells derived from adipose tissue of wild rodent agouti (Dasyprocta prymnolopha). Arquivo Brasileiro de Medicina Veterinária e Zootecnia. 2019, 71(5), 1571-1581. https://doi.org/10.1590/1678$\underline{4162-10677}$

ROCHA, M.A.C., et al. Allogeneic mesenchymal stem cells and xenogenic platelet rich plasma, associated or not, in the repair of bone failures in rabbits with secondary osteoporosis. Acta Cirurgica Brasileira. 2017, 32(9), 767-780. http://dx.doi.org/10.1590/s0102-865020170090000009

SARGIACOMO, C., et al. Upregulation of sodium taurocholate cotransporter polypeptide during hepatogenic differentiation of umbilical cord matrix mesenchymal stem cells facilitates hepatitis B entry. Stem Cell Research \& Therapy. 2017, 8(1), 204. https://doi.org/10.1186/s13287$\underline{017-0656-5}$

SIRONI, F., et al. Multiple intracerebroventricular injections of human umbilical cord mesenchymal stem cells delay motor neurons loss but not disease progression of SOD1G93A mice. Stem Cell Research. 2017, 25, 166-178. https://doi.org/10.1016/i.scr.2017.11.005

SOARES, I.M.V. et al. The influence of Aloe vera with mesenchymal stem cells from dental pulp on bone regeneration: characterization and treatment of non-critical defects of the tibia in rats. Journal of Applied Oral Science. 2019, 27, e20180103. https://doi.org/10.1590/1678-7757$\underline{2018-0103}$

TAGHIZADEH, R.R.; CETRULO, K.J. and CETRULO, C.L. Wharton's Jelly stem cells: future clinical applications. Placenta. 2011 , 32, S311-S315. https://doi.org/10.1016/j.placenta.2011.06.010

VOLAREVIC, V., et al. Stem cells as new agents for the treatment of infertility: current and future perspectives and challenges. BioMed Research International. 2014, 2014, 507234. https://doi.org/10.1155/2014/507234

$\mathrm{XIE}$, J., et al. Umbilical cord-derived mesenchymal stem cells alleviated inflammation and inhibited apoptosis in interstitial cystitis via AKT/mTOR signaling pathway. Biochemical and Biophysical Research Communications. 2018, 495(1), 546-552.

https://doi.org/10.1016/j.bbrc.2017.11.072

Received: 14 September 2019 | Accepted: 16 March 2020 | Published: 12 January 2021

This is an Open Access article distributed under the terms of the Creative Commons Attribution License, which permits unrestricted use, distribution, and reproduction in any medium, provided the original work is properly cited. 